\title{
中国南方灌丛凋落物现存量
}

\author{
葛结林 ${ }^{1}$ 熊高明 ${ }^{1} \quad$ 李家湘 $^{1} \quad$ 徐文婷 $^{1} \quad$ 赵常明 ${ }^{1} \quad$ 卢志军 $^{2} \quad$ 李跃林 $^{3}$ 谢宗强 $^{1^{*}}$ \\ ${ }^{1}$ 中国科学院植物研究所植被与环境变化国家重点实验室, 北京 $100093 ;{ }^{2}$ 中国科学院武汉植物园水生植物与流域生态院重点实验室, 武汉 $430074 ;$ \\ ${ }^{3}$ 中国科学院华南植物园, 广州 510650
}

摘 要 调落物是陆地生态系统的重要组成部分, 在区域尺度上阐明其现存量的分布特征及其影响因子有助于理解陆地生 态系统碳循环的机理。该研究采用分层随机抽样调查方法分析了中国南方灌从生态系统调落物现存量的空间分布格局及其影 响因子。结果发现: 该区域灌从调落物现存量的平均值为 $0.32 \mathrm{~kg} \cdot \mathrm{m}^{-2}$, 是中国森林调落物现存量 $\left(0.47 \mathrm{~kg} \cdot \mathrm{m}^{-2}\right)$ 的 $68 \%$, 是中国 草地调落物现存量 $\left(0.06 \mathrm{~kg} \cdot \mathrm{m}^{-2}\right)$ 的 5 倍; 调落物现存量呈现出明显的纬度格局, 随着纬度的增加而升高; 该区域的灌从生态系 统调落物现存量的碳转换系数为 0.41 , 显著低于植被活体转换系数 0.50 ; 调落物现存量与年平均气温、土壤全磷含量和土壤 $\mathrm{pH}$ 值显著负相关，与年降水量、土壤碳、氮以及有机碳含量相关性不显著。研究表明: 该区域灌丛调落物现存量是中国陆地 生态系统碳库不可忽视的组分; 年平均气温是影响该区域内灌从生态系统调落物现存量的重要环境因子; 采用常用的植被 活体碳转换系数可能会高估调落物现存量碳库的 $22 \%$ 。

关键词 调落物的累积; 空间格局; 碳转换系数; 年平均气温; 土壤属性; 气候

引用格式: 葛结林, 熊高明, 李家湘, 徐文婷, 赵常明, 卢志军, 李跃林, 谢宗强 (2017). 中国南方灌丛调落物现存量. 植物生态学报, 41, 5-13. doi: $10.17521 /$ cjpe.2016.0202

\section{Litter standing crop of shrubland ecosystems in southern China}

GE Jie-Lin ${ }^{1}$, XIONG Gao-Ming ${ }^{1}$, LI Jia-Xiang ${ }^{1}$, XU Wen-Ting ${ }^{1}$, ZHAO Chang-Ming ${ }^{1}$, LU Zhi-Jun ${ }^{2}$, LI Yue-Lin ${ }^{3}$, and XIE Zong-Qiang ${ }^{*}$

${ }^{1}$ State Key Laboratory of Vegetation and Environmental Change, Institute of Botany, Chinese Academy of Sciences, Beijing 100093, China; ${ }^{2}$ Key Laboratory of Aquatic Botany and Watershed Ecology, Wuhan Botanical Garden, Chinese Academy of Sciences, Wuhan 430074, China; and ${ }^{3}$ South China Botanical Garden, Chinese Academy of Sciences, Guangzhou 510650, China

\section{Abstract}

Aims Litter is an important component of terrestrial ecosystems, which plays significant roles in carbon and nutrient cycles. Quantifying regional-scale pattern of litter standing crop would improve our understanding in the mechanism of the terrestrial ecosystem carbon cycle, also with help in predicting the responses of carbon cycle of terrestrial ecosystems to future climate change. Our objective was to examine variation in litter standing crop of shrublands along the environmental gradients in southern China.

Methods During 2011-2014, we investigated the litter standing crop at 453 shrublands sites by the stratified random sampling, reflecting climatic and soil attributes across southern China.

Important findings We found that the mean value of litter standing crop in these shrubland ecosystems across southern China was $0.32 \mathrm{~kg} \cdot \mathrm{m}^{-2}$. It was $68 \%$ of forest litter standing crop $\left(0.47 \mathrm{~kg} \cdot \mathrm{m}^{-2}\right)$ and was five times higher than that in grasslands $\left(0.06 \mathrm{~kg} \cdot \mathrm{m}^{-2}\right)$ in China. Litter standing crop increased with latitude. Our results showed that litter standing crop was negatively correlated with mean annual temperature, soil total $\mathrm{P}$ and soil $\mathrm{pH}$, but not significantly correlated with other environmental variables, including mean annual precipitation, soil carbon, nitrogen and soil organic matter. The conversion coefficient of carbon in litter standing crop was 0.41, which is significantly lower than that of vegetation in shrublands (0.50), resulting in an overestimate in carbon storage of litter standing crop in shrubland up to $22 \%$ by applying wrong conversion coefficient. We concluded that litter standing crop of shrublands is an important component in terrestrial ecosystems. Mean annual temperature was the most important environmental variable, accounting for the variation in litter standing crop of shrublands in southern China. To our best of knowledge, this is the first study to quantify variation in litter standing crop of shrublands at the regional scale. Therefore, our study will have important implications for assessing the carbon budget of

收稿日期Received: 2016-06-14 接受日期Accepted: 2016-11-10

* 通信作者Author for correspondence (E-mail: xie@ibcas.ac.cn) 
terrestrial ecosystems in China.

Key words accumulation of litter; spatial pattern; conversion coefficient of carbon; mean annual temperature; soil attribute; climate

Citation: Ge JL, Xiong GM, Li JX, Xu WT, Zhao CM, Lu ZJ, Li YL, Xie ZQ (2017). Litter standing crop of shrubland ecosystems in southern China. Chinese Journal of Plant Ecology, 41, 5-13. doi: 10.17521/cjpe.2016.0202

调落物也称枯落物，是由植被地上部分产生并 归还到地表的所有有机物质的总称(彭少麟和刘强, 2002; Parsons et al., 2014a; Domke et al., 2016)。调落 物的生产、积累以及分解是调落物研究的重要内容 (Descheemaeker et al., 2006; Parsons et al., 2014b)。 调落物现存量又称调落物的累积量, 通常指一定面 积上特定生态系统地表堆积的调落物的质量, 反映 植被调落层在时间和空间上现存调落物的多少, 是 调落物输入和输出(分解)后的净积累量, 可被看作 是不同分解阶段和状态的调落物的复合体(阎恩荣 等, 2008; Hilli et al., 2010; Domke et al., 2016)。当调 落物从植物体脱落进入地表时, 就开始了物理、化 学和生物的分解过程, 通过这些过程释放出生态系 统所需要的养分和 $\mathrm{CO}_{2}$, 从而参与陆地生态系统的 物质循环和能量流动过程。因此, 准确地评估调落 物现存量对揭示陆地生态系统碳循环具有重要的生 态学意义(Descheemaeker et al., 2006; Marty et al., 2015; Domke et al., 2016)。

目前, 与调落物的产量和分解的研究(汪思龙 和陈楚莹, 2010; 唐仕姗等, 2014; García-Palacios et al., 2016)相比, 对调落物现存量的研究相对较少, 多局限于单个地点的研究(郑路和卢立华, 2012; Portillo-Estrada et al., 2016), 对大尺度调落物现存 量格局及其气候控制因子的认识仍不清楚。调落物 现存量受调落物产量和分解量的动态关系决定 (Twilley et al., 1986; 马玉珠等, 2013)。因此, 影响调 落物产量和分解过程的因素都会对调落物的现存量 产生重要影响(张新平等, 2008; 李强等, 2014), 推 测调落物的现存量同样受到这些因子的制约。然而, 调落物的产量和分解对不同环境因子的响应存在差 异。有研究表明, 调落物的产量主要受年平均气温 的制约(Liu et al., 2004; 吕国红等, 2014), 而调落物 的分解通常与年平均气温、年降水量有关, 其控制 因子一般因研究地区而异(赵红梅等, 2012; Zhang \& Wang, 2015)。因此, 调落物的现存量是否存在一定 的空间分布格局, 目前尚缺乏相应的实证研究
(Simmons et al., 1996; Descheemaeker et al., 2006; Westcott et al., 2014)。

灌从作为陆地生态系统中最重要的自然植被类 型, 在群落演替、生态系统碳固持和生物多样性保 育等方面扮演着不可替代的角色(Piao et al., 2009; 方精云等, 2015b)。中国灌丛面积为 69.2 万 $\mathrm{km}^{2}$, 是全 球灌丛分布面积最广泛的国家(胡会峰等, 2006; 中 华人民共和国环境保护部和中国科学院, 2015)。目 前, 对调落物现存量的研究主要集中在森林和草地 (Parsons et al., 2014b; 方精云等, 2015a; 温丁和何 念鹏, 2016), 而对占国土面积7.3\%的灌从生态系统 调落物现存量的关注和研究还远远不够。而且, 灌 从面积增加引起的碳储量增加被认为是我国陆地 生态系统碳储量增加的主要原因, 也是陆地生态 系统碳汇研究中一个最不确定的因素(胡会峰等, 2006)。

鉴于此, 本研究通过调查中国南方灌从生态系 统的调落物现存量, 系统阐明其空间分布格局及其 主要控制因子, 旨在加深对调落物现存量与其影响 因素之间关系的理解, 为补充完善我国区域尺度上 调落物研究提供一定的科学依据。

\section{1 研究方法}

\section{1 研究区域}

研究区位于我国南方江苏、浙江、安徽、湖北、 江西、福建、广东、湖南、重庆、广西、海南等11 个省市自治区。地理范围 $18.26^{\circ}-34.63^{\circ} \mathrm{N}, 105.17^{\circ}$ $121.26^{\circ} \mathrm{E}$, 海拔0-1 $865 \mathrm{~m}$ 。各省调查地点的气候和 土壤状况详见表1。

\section{2 凋落物现存量的收集与分析}

按照分层随机抽样调查方法，2011-2014年7月 和8月在中国南方灌从生态系统共调查453个样点。 在每个样点设置 3 个 $5 \mathrm{~m} \times 5 \mathrm{~m}$ 的重复样方。调查样 方的物种组成, 并在每个样方内选取 1 个 $1 \mathrm{~m} \times 1 \mathrm{~m}$ 的小样方收集全部地表调落物, 称质量后取样。将 取回的调落物于 $65{ }^{\circ} \mathrm{C}$ 下烘干至恒质量得出干质量。 
表1 所研究省市自治区的地理位置、气候和土壤养分概况

Table 1 General information on geographic location, climate and soil for different provinces, municipalities and autonomous regions

\begin{tabular}{|c|c|c|c|c|c|c|c|c|c|c|}
\hline $\begin{array}{l}\text { 地点 } \\
\text { Place }\end{array}$ & $\begin{array}{l}\text { 年份 } \\
\text { Year }\end{array}$ & $\begin{array}{l}\text { 样点数 } \\
\text { No. of } \\
\text { sites }\end{array}$ & $\begin{array}{l}\text { 纬度 } \\
\text { Latitude }\left(^{\circ}\right) \\
(\mathrm{N})\end{array}$ & $\begin{array}{l}\text { 经度 } \\
\text { Longitude }\left(^{\circ}\right) \\
\text { (E) }\end{array}$ & $\begin{array}{l}\text { 海拔 } \\
\text { Altitude } \\
\text { (m) }\end{array}$ & $\begin{array}{c}\text { 年平均气温 } \\
\text { Mean annual } \\
\text { temperature } \\
\left({ }^{\circ} \mathrm{C}\right)\end{array}$ & $\begin{array}{c}\text { 年降水量 } \\
\text { Mean annual } \\
\text { precipitation } \\
(\mathrm{mm})\end{array}$ & $\begin{array}{c}\text { 土壤全碳 } \\
\text { Soil total } \\
\text { carbon } \\
(\%)\end{array}$ & $\begin{array}{l}\text { 土壤全氮 } \\
\text { Soil total } \\
\text { nitrogen } \\
\text { (\%) }\end{array}$ & $\begin{array}{c}\text { 土壤全磷 } \\
\text { Soil total } \\
\text { phosphorus } \\
\left(\mathrm{mg} \cdot \mathrm{g}^{-1}\right)\end{array}$ \\
\hline 江苏 Jiangsu & 2012-2013 & 5 & $31.6-34.6$ & 118.1-120.3 & 18-388 & 16.1 & 1019.6 & 1.4 & 0.1 & 0.5 \\
\hline 浙江 Zhejiang & 2011-2013 & 26 & 27.5-31.1 & $118.4-122.3$ & $27-631$ & 18.2 & 1784.3 & 1.8 & 0.2 & 0.3 \\
\hline 安徽 Anhui & 2011-2012 & 20 & 29.7-31.6 & 115.9-119.4 & $47-553$ & 17.2 & 1692.1 & 2.1 & 0.2 & 0.5 \\
\hline 湖北 Hubei & 2011-2013 & 74 & 29.1-32.9 & 108.7-115.8 & $61-1865$ & 16.3 & 1375.2 & 2.3 & 0.2 & 0.6 \\
\hline 江西 Jiangxi & 2011-2013 & 49 & $25.0-29.6$ & 113.9-117.5 & 28-601 & 20.0 & 1641.0 & 1.7 & 0.2 & 0.4 \\
\hline 福建 Fujian & 2011-2013 & 39 & $24.1-27.9$ & $116.4-120.2$ & $42-1132$ & 20.3 & 1795.1 & 1.3 & 0.1 & 0.2 \\
\hline 广东 Guangdong & 2011-2014 & 35 & $21.7-25.0$ & 111.3-116.5 & $0-678$ & 22.6 & 2009.2 & 2.2 & 0.2 & 0.3 \\
\hline 湖南 Hunan & 2011-2013 & 70 & 25.1-29.7 & 109.6-113.9 & $61-1405$ & 18.6 & 1547.3 & 2.5 & 0.2 & 0.4 \\
\hline 重庆 Chongqing & 2011-2013 & 50 & $28.5-32.0$ & 105.9-110.0 & 173-1 506 & 16.8 & 1355.3 & 2.9 & 0.2 & 0.6 \\
\hline 广西 Guangxi & 2011-2014 & 44 & $21.7-25.0$ & $105.2-111.4$ & $33-1259$ & 22.0 & 1669.8 & 3.0 & 0.3 & 0.8 \\
\hline 海南 Hainan & 2011-2012 & 20 & 18.3-20.0 & 108.7-111.0 & $4-147$ & 26.1 & 1569.3 & 0.9 & 0.1 & 0.4 \\
\hline
\end{tabular}

对调落物按粗大枝条、枝条、小枝条、叶、皮、花 果等进行分类并取样, 采用 $\mathrm{C} / \mathrm{N}$ 元素分析仪(vario MACRO cube, Elementar, Hanau, Germany)分析调 落物中的碳浓度, 并计算该区域调落物现存量的碳 转换系数。具体采样方法见 《生态系统固碳观测与 调查技术规范》一书(生态系统固碳项目技术规范编 写组, 2015)。

\section{3 环境数据的获取}

\subsection{1 气候数据的获取}

通过调落物收集地点的地理坐标, 从世界气候 数据库(http://www.worldclimate.org/) 中获取研究地 点的气候变量: 年平均气温(MAT)和年降水量 (MAP)(Hijmans et al., 2005), 并根据上述指标推算 干燥度(climatic dryness, $I_{\mathrm{dw}}$ )。计算公式如下: $I_{\mathrm{dw}}=$ $M A P /(M A T+10)$ (Zhang \& Wang, 2015; 温丁和何念 鹏, 2016)。

\subsection{2 土壤数据的获取}

在每个样点选取最具有代表性的位置, 垂直于 地面挖取一个 $1 \mathrm{~m}$ 深的土壤剖面; 对土壤剖面按照 以下层次进行划分: 1-10、10-20、20-30、30-50、 50-70和70-100 cm, 并进行环刀和土柱分层取样。 环刀取样用于测量土壤容重, 土柱取样则用于测量 土壤有机碳、 $\mathrm{pH}$ 值以及土壤养分含量, 测定方法参 考《土壤理化分析与剖面描述》一书(刘光崧, 1997)。 本研究采用表层0-10 cm土壤样品。

\section{4 数据分析}

首先对灌丛生态系统调落物现存量进行描述
性统计, 获取数据的分布及变异程度。其次, 检验数 据分布的正态性, 并对不符合正态分布的变量进行 对数转换(本研究对调落物现存量、土壤全 $\mathrm{C} 、 \mathrm{~N} 、 \mathrm{P}$ 以及土壤有机碳作自然对数转换), 用于以下分析: 采用单因素方差分析比较不同类型灌从(常绿和落 叶)之间的差异; 采用相关性分析和简单线性回归 分析不同环境因子对调落物现存量的影响, 并通过 逐步向后回归分析和方差分解的方法计算不同环境 因子对调落物现存量变异特征的相对贡献(RayMukherjee et al., 2014)。所有统计分析采用 R软件 (http://www.rproject.org)来实现。

\section{2 研究结果}

\section{1 凋落物现存量及其碳转换系数}

中国南方灌丛生态系统调落物现存量存在较大 的标准偏差和变异系数, 呈现出正偏态分布(图1)。 灌从凋落物现存量的平均值为 $0.32 \mathrm{~kg} \cdot \mathrm{m}^{-2}$, 最小值 为 $0.03 \mathrm{~kg} \cdot \mathrm{m}^{-2}$, 最大值为 $2.90 \mathrm{~kg} \cdot \mathrm{m}^{-2}$ 。单因素方差分 析发现, 常绿和落叶灌从的调落物现存量差别不显 著 $(p>0.05)$ 。该地区灌丛生态系统调落物现存量的 碳转换系数为 0.41 。

\section{2 凋落物现存量的空间分布格局}

中国南方灌丛生态系统调落物现存量存在较弱 的线性空间分布格局。因此, 为了更清楚地探讨它 们的空间分布格局, 本研究将数据按照 $2^{\circ}$ 的经度和 纬度间隔进行整合, 以揭示调落物现存量随经纬 度的变化趋势。结果发现: 中国南方灌从调落物 


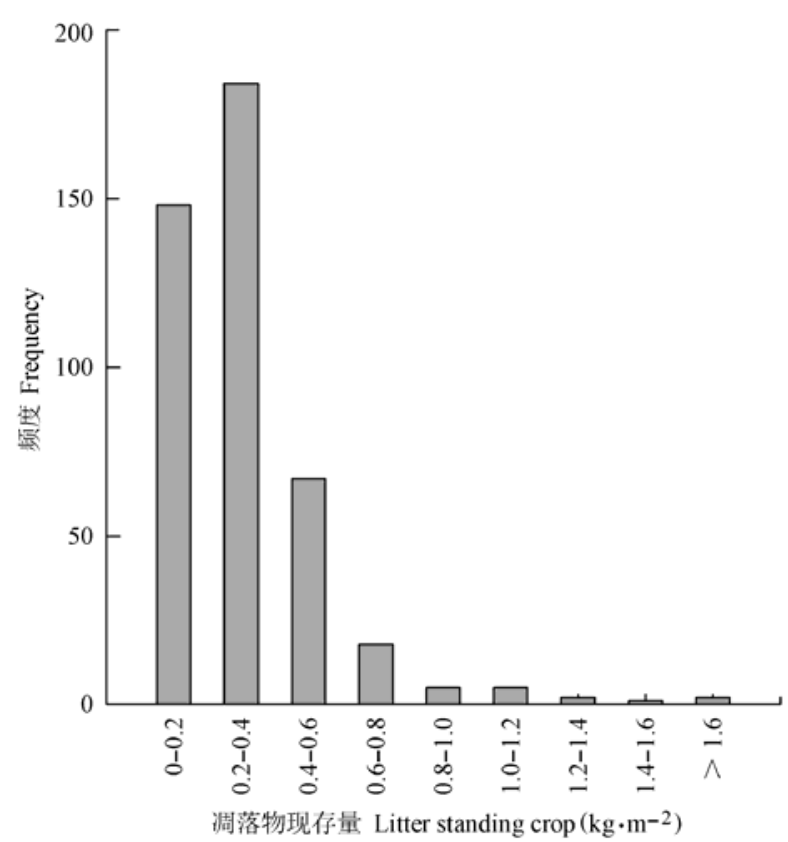

图1 中国南方灌丛调落物现存量的频度分布图。

Fig. 1 Frequency distribution of litter standing crop of shrublands in southern China.

的现存量在不同纬度和经度间表现出较大的变异特 征; 灌丛调落物现存量存在显著的纬度格局 $(F=$ 4.96, $p<0.001)$, 随着纬度的增加而增加 $(p<0.001)$, 但经度格局不明显 $(p>0.05)($ 图2)。

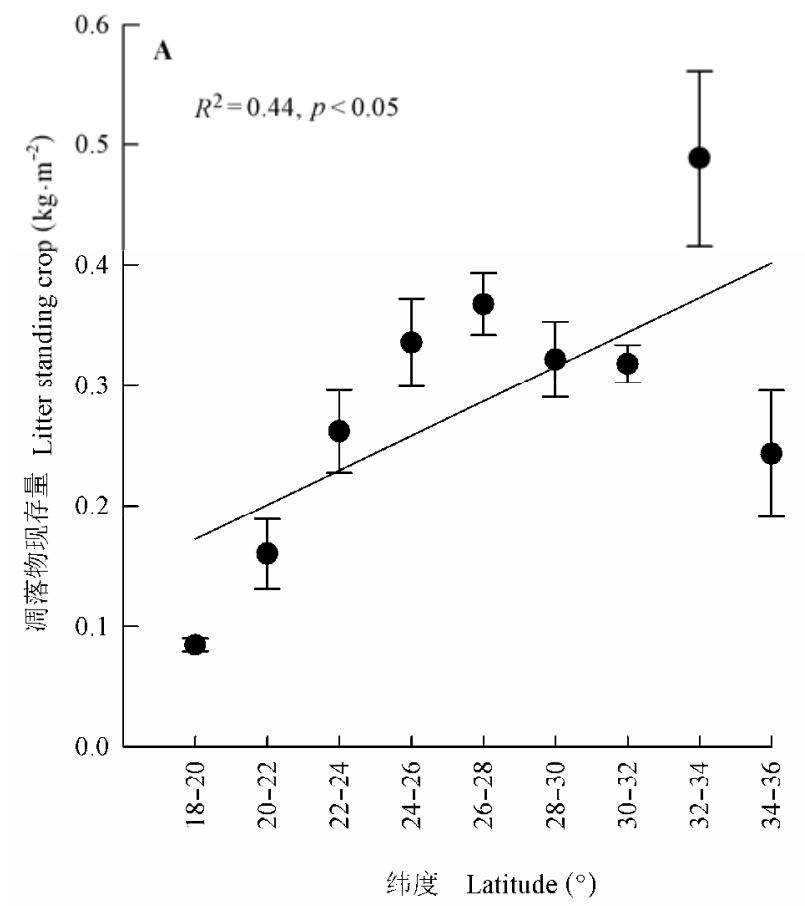

\section{3 凋落物现存量与环境因子之间的关系}

简单线性回归分析发现, 调落物现存量与年平 均气温、土壤磷含量、 $\mathrm{pH}$ 值和土壤容重呈现显著的 负相关关系 $(p<0.05)$, 与干燥度正相关 $(p<0.05)$, 而与其他环境因子(年降水量、土壤碳、氮以及有机 碳含量)的相关性不显著 $(p>0.05)$ (图3)。进一步采用 逐步向后回归分析表明，调落物现存量与年平均气 温、土壤全磷含量和土壤 $\mathrm{pH}$ 值显著负相关 $(p<0.05)$ 。 方差分解发现年平均气温对调落物现存量的变异解 释率最大, 占上述多元线性模型解释率的 $67.33 \%$ 。

\section{3 讨论}

\section{1 中国南方灌丛凋落物现存量的分布格局}

本研究发现, 中国南方灌从生态系统的调落物 现存量为 $0.32 \mathrm{~kg} \cdot \mathrm{m}^{-2}$, 是中国灌丛植被生物量(胡会 峰等, 2006)的0.15倍。该地区灌丛生态系统的调落 物现存量与全球灌从生态系统调落物现存量 (0.33 $\mathrm{kg} \cdot \mathrm{m}^{-2}$ )(Matthews, 1997)相当(本文作者根据文献近 似推算), 是中国森林调落物现存量 $\left(0.47 \mathrm{~kg} \cdot \mathrm{m}^{-2}\right)$ (温丁和何念鹏, 2016)的0.68倍, 是中国草地调落物 现存量 $\left(0.06 \mathrm{~kg} \cdot \mathrm{m}^{-2}\right)$ (温丁和何念鹏, 2016)的5倍。

灌从生态系统的调落物现存量随纬度增加而增 加, 该研究结果与对中国森林的研究结论一致, 而

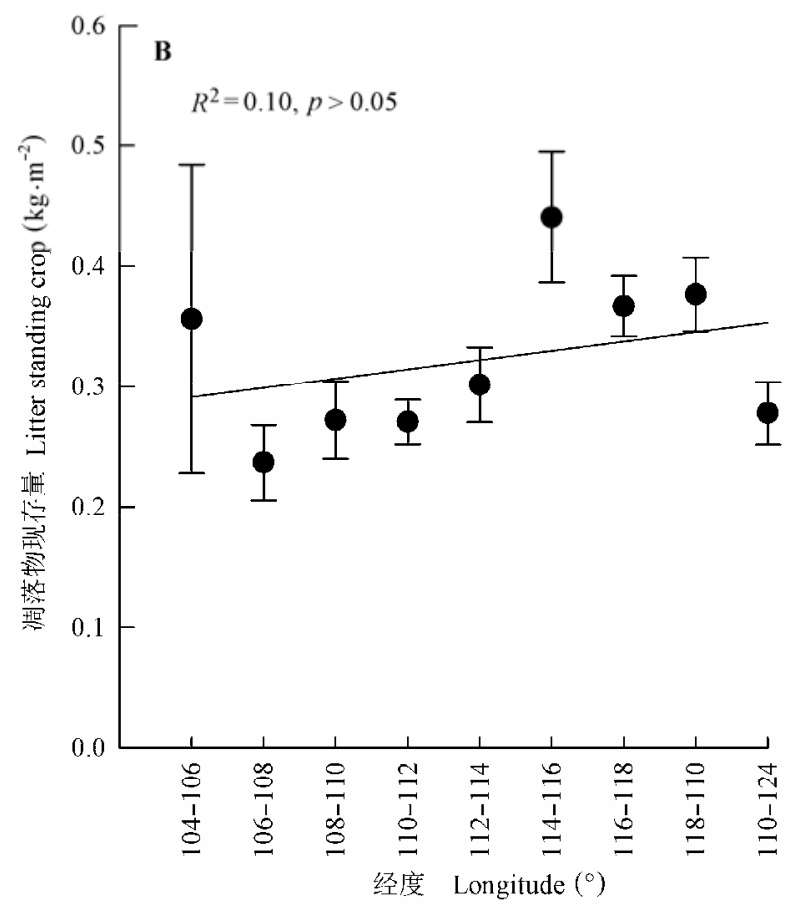

图2 中国南方灌从调落物现存量随经纬度的变化(平均值沶准误差)。A, 纬度。 $\mathbf{B}$, 经度。

Fig. 2 Variation in litter standing crop of shrublands across the latitudinal and longitudinal gradients in southern China (mean $\pm S E$ ). A, Latitude. B, Longitude. 

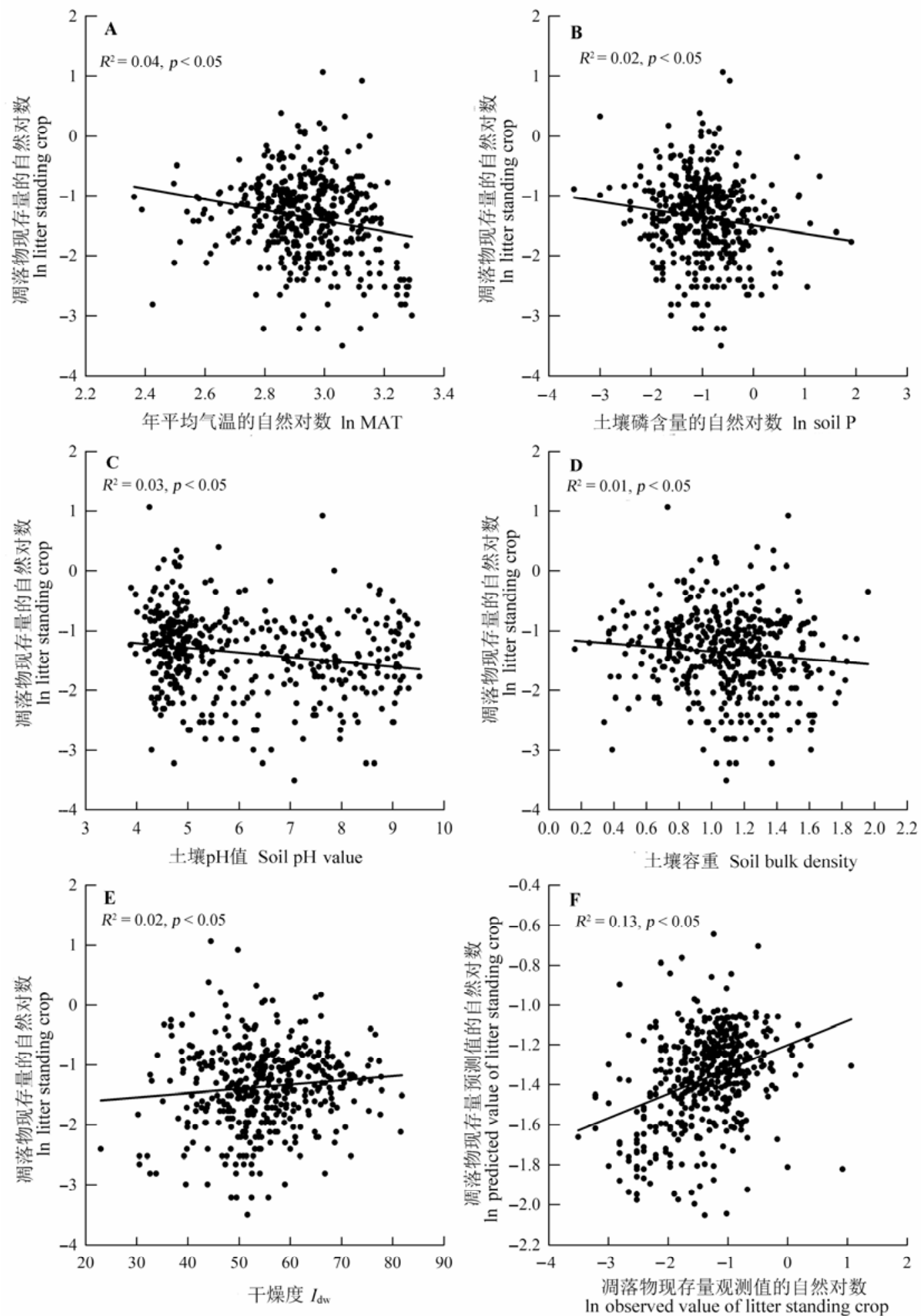

图3 中国南方灌丛调落物现存量与环境因子的关系。本文仅显示调落物现存量与环境因子关系显著的图。A-E, 现存量与单 个环境因子(年平均气温、土壤全磷含量、土壤容重和干燥度)的关系。F, 现存量与年平均气温(MAT)、土壤全磷含量和土壤 $\mathrm{pH}$ 值之间的多元线性回归关系。

Fig. 3 Variation in litter standing crop of shrublands of southern China in relation to environmental factors in China. We only showed the figures that depicted the significant relationship between litter standing crop and environmental factors. A-E, The relationship between litter standing crop and single environmental variables including mean annual temperature (MAT), soil total phosphorus $(\mathrm{P})$ content, soil $\mathrm{pH}$ value, soil bulk density and climatic dryness $\left(I_{\mathrm{dw}}\right)$. F, Observed value vs. predicted value of litter standing crop from multiple regression using mean annual temperature (MAT), soil $\mathrm{P}$ content and soil $\mathrm{pH}$ value as predictors. 
与对中国草地的研究(温丁和何念鹏, 2016)结论相 反。该结果表明, 森林生态系统调落物现存量的控 制因子与灌从生态系统相似, 与中国草地生态系统 不一致。因此, 本研究认为以木本植物组成为主的 生态系统(如森林和灌丛)的调落物现存量与以草本 植物组成为主的生态系统(如草地)的主控因子差异 明显。原因与不同生态系统类型的空间分布有关。 森林和灌丛的分布区域内降水一般较为丰富, 其分 布一般受到温度的制约; 而草地主要分布于干旱和 半干旱区域(吴征镒, 1980)。因此不同类型生态系统 的干物质生产和分解受到上述环境因子的制约, 从 而导致凋落物现存量在不同生态系统中的控制因子 差异明显。

中国南方灌从凋落物现存量表现出较明显的纬 度格局, 经度格局不明显。由于同一地区不同样点 间调落物现存量存在较大的变异(图2), 即局域尺度 上存在较大的取样效应, 降低了区域尺度上调落物 现存量的纬度格局, 表现出显著的线性关系但解释 力较低 $\left(R^{2}\right.$ 较小)。该现象在森林和草地生态系统中 同样存在(温丁和何念鹏, 2016)。本研究中所采用的 不同样点的数据均是采用统一规范的方法进行采 样, 取样时间和方法不是造成局部地点凋落物现存 量出现较大变异的主要原因。造成同一地区不同样 点间变异的可能原因包括: 1)同一地点的地形和地 貌的差异。不同地形和地貌环境下灌从的物种组成 差异较大, 物种间的物候特征差异较为明显, 影响 了灌木物种器官的更新和衰老, 调落物的产量和分 解速率差异明显, 因此造成地表调落物现存量变异 较大。2)灌丛所处的演替阶段的不同。在中国南方 地区, 地带性植被是森林, 灌丛一般是该地区森林 演替过程中的一个重要阶段(吴征镒, 1980)。受到人 为和自然干扰的强度差异, 使同一地点内灌从生态 系统经常处于不稳定的状态, 其物种组成和多样性 随之不稳定, 因此其调落物现存量变异较大 (Domke et al., 2016)。该研究结果也说明, 开展局域 尺度上的灌从凋落物现存量的研究很有必要。

\section{2 中国南方灌丛凋落物现存量的影响因子}

陆地生态系统调落物的现存量受到多种环境因 素共同控制, 大尺度上水分和热量通过控制植被类 型影响调落物的产量和分解, 进而影响调落物的现 存量(Zhou et al., 2009; Chave et al., 2010)。本研究发 现, 中国南方灌丛生态系统的调落物现存量地理格
局受到年平均气温、土壤 $\mathrm{pH}$ 值以及土壤全磷含量等 因子的制约, 但最重要的环境因子是年平均气温。 这与前人对调落物产量和分解的研究结果(Descheemaeker et al., 2006; Pitkänen et al., 2012)一致。年 平均气温是植物生长所需要的基本环境条件, 其年 际间变化影响植物的物候变化, 从而制约着调落物 的产量。凋落物现存量受到调落物生产和分解的制 约(Hill et al., 2010)。大量研究表明, 调落物的产量 与年平均气温显著正相关(张新平等, 2008; Salinas et al., 2011; 吕国红等, 2014), 不考虑调落物的分解 时, 调落物的现存量应与年平均气温成正比, 但本 研究发现凋落物现存量与年平均气温成反比。因此, 调落物的分解可能是影响中国南方灌从调落物现存 量空间分布的关键过程。上述推断与前人关于调落 物分解自然气候梯度的研究(Zhang et al., 2008; Hilli et al., 2010)一致。不同的研究发现, 随着纬度增加, 调落物的分解速率下降, 温度升高可以显著加快不 同生态系统的地表调落物的分解(Aerts, 1997; Dorrepaal et al., 2005; Zhang \& Wang, 2015)。例如, Dorrepaal等(2005)研究欧洲西北部的灌木物种分解 时发现, 年平均气温是与灌木树种调落物分解速率 最密切的控制因子。同样Hilli等(2010)研究森林凋落 物分解对调落物储量的影响时发现凋落物分解过程 是调落物储量空间变异的最为关键过程。本研究位 于热带和亚热带地区, 温度是影响灌从凋落物产量 和分解的限制因子, 对调落物分解的影响程度更突 出, 因此年平均气温对调落物生产和分解之间作用 的差异性是导致中国南方灌从生态系统调落物现存 量空间分异的主要原因。

\section{3 中国南方灌丛凋落物现存量的碳转换系数}

碳转换系数是研究陆地生态系统碳收支的重要 参数。本研究发现, 中国南方灌丛调落物现存量的 碳转换系数为 0.41 , 低于前人研究灌从生态系统所 采用的植被活体碳转换系数 (0.50)(胡会峰等, 2006)。因此在研究灌从生态系统碳储量时, 采用常 用的植被活体碳转换系数可能会高估灌从生态系统 调落物碳储量 $22 \%$ 。调落物现存量的碳转换系数与 碳浓度相关, 受到环境因子、调落物的类型(叶、小 枝、花果等)、调落物的分解程度制约(陈莎莎等, 2010)。在不同的环境梯度下, 灌丛生态系统生产的 调落物的种类和组成差异明显, 进而造成调落物在 进入地表时碳浓度发生改变。一般而言, 在年平均 
气温较低时, 植物为响应低温环境会产生较高碳含 量的有机物, 而碳元素在器官调落时一般很少被重 新吸收(Vergutz et al., 2012; Schreeg et al., 2013; Sun et al., 2016), 因此导致进入地表前调落物中碳浓度 保持稳定。而进入地表的调落物随着分解的进行, 碳 浓度会下降。上述过程相互作用, 使得调落物现存量 中的碳浓度低于植被活体碳浓度, 从而造成区域尺 度上调落物现存量的碳转换系数低于植被活体。

\section{4 结论}

中国南方灌丛生态系统的调落物现存量是陆地 生态系统不可忽视的组成部分, 其平均值为 0.32 $\mathrm{kg} \cdot \mathrm{m}^{-2}$; 该区域灌从调落物现存量随着纬度的增加 而升高; 年平均气温是影响南方灌从生态系统调落 物现存量的重要环境因子; 在评估灌从生态系统碳 储量时, 采用常用的植被活体碳转换系数可能会高 估灌从生态系统调落物现存量的碳储量的 $22 \%$ 。本 研究首次在区域尺度上采用统一和规范的取样方法 分析了我国南方灌丛生态系统调落物现存量, 为评 估我国陆地生态系统的碳收支提供了重要的科学 依据。

基金项目中国科学院战略性先导科技专项 (XDA05050302)。

致谢 项目野外调查和室内分析中得到中南林业科 技大学的学生以及湖北神农架森林生态系统国家野 外科学观测研究站监测人员的大力帮助, 在此表示 感谢!

\section{参考文献}

Aerts R (1997). Climate, leaf litter chemistry and leaf litter decomposition in terrestrial ecosystems: A triangular relationship. Oikos, 79, 439-449.

Chave J, Navarrete D, Almeida S, Alvarez E, Aragão LE, Bonal D, Châtelet P, Silva-Espejo J, Goret JY, Hildebrand P (2010). Regional and seasonal patterns of litterfall in tropical South America. Biogeosciences, 7, 43-55.

Chen SS, Liu HY, Guo DL (2010). Litter stocks and chemical quality of natural birch forest along temperature and precipitation gradients in eastern Inner Mongolia, China. Chinese Journal of Plant Ecology, 34, 1007-1015. (in Chinese with English abstract) [陈莎莎, 刘鸿雁, 郭大立 (2010). 内蒙古东部天然白桦林的调落物性质和储量及 其随温度和降水梯度的变化格局. 植物生态学报, 34, 1007-1015.]

Descheemaeker K, Muys B, Nyssen J, Poesen J, Raes D, Haile
M, Deckers J (2006). Litter production and organic matter accumulation in exclosures of the Tigray highlands, Ethiopia. Forest Ecology and Management, 233, 21-35.

Domke GM, Perry CH, Walters BF, Woodall CW, Russell MB, Smith JE (2016). Estimating litter carbon stocks on forest land in the United States. Science of Total Environment, 557, 469-478.

Dorrepaal E, Cornelissen JHC, Aerts R, Wallén B, van Logtestijn RSP (2005). Are growth forms consistent predictors of leaf litter quality and decomposability across peatlands along a latitudinal gradient? Journal of Ecology, 93, 817-828.

Fang JY, Huang Y, Zhu JL, Sun WJ, Hu HF (2015a). Carbon budget of forest ecosystems and its driving forces. China Basic Science, 3, 20-25. (in Chinese with English abstract) [方精云, 黄耀, 朱江玲, 孙文娟, 胡会峰 (2015a). 森 林生态系统碳收支及其影响机制. 中国基础科学, 3, 20-25.]

Fang JY, Yu GR, Ren XB, Liu GH, Zhao XQ (2015b). Carbon sequestration in China's terrestrial ecosystems under climate change-Progress on ecosystem carbon sequestration from the CAS Strategic Priority Research Program. Bulletin of Chinese Academy of Sciences, 30, 848-857. (in Chinese with English abstract) [方精云, 于贵瑞, 任小波, 刘国华, 赵新全 (2015b). 中国陆地生态系统固碳效应 一中国科学院战略性先导科技专项“应对气候变化的 碳收支认证及相关问题”之生态系统固碳任务群研究进 展. 中国科学院院刊, 30, 848-857.]

García-Palacios P, McKie BG, Handa IT, Frainer A, Hättenschwiler S (2016). The importance of litter traits and decomposers for litter decomposition: A comparison of aquatic and terrestrial ecosystems within and across biomes. Functional Ecology, 30, 819-829.

Hijmans RJ, Cameron SE, Parra JL, Jones PG, Jarvis A (2005). Very high resolution interpolated climate surfaces for global land areas. International Journal of Climatology, 25, 1965-1978.

Hilli S, Stark S, Derome J (2010). Litter decomposition rates in relation to litter stocks in boreal coniferous forests along climatic and soil fertility gradients. Applied Soil Ecology, 46, 200-208.

Hu HF, Wang ZH, Liu GH, Fu BJ (2006). Vegetation carbon storage of major shrublands in China. Journal of Plant Ecology (Chinese Version), 30, 539-544. (in Chinese with English abstract) [胡会峰, 王志恒, 刘国华, 傅伯杰 (2006). 中国主要灌从植被碳储量. 植物生态学报, 30, 539-544.]

Li Q, Zhou DW, Chen XY (2014). The accumulation, decomposition and ecological effects of above-ground litter in terrestrial ecosystem. Acta Ecologica Sinica, 34, 3807-3819. (in Chinese with English abstract) [李强, 周 
道玮，陈笑莹 (2014). 地上枯落物的累积、分解及其在 陆地生态系统中的作用. 生态学报, 34, 3807-3819.]

Liu C, Westman CJ, Berg B, Kutsch W, Wang GZ, Man R, Ilvesniemi H (2004). Variation in litterfall-climate relationships between coniferous and broadleaf forests in Eurasia. Global Ecology and Biogeography, 13, 105-114.

Liu GS (1997). Soil Physical and Chemical Analysis and the Profile Description. China Standard Publishing House, Beijing. (in Chinese) [刘光崧 (1997). 土壤理化分析与 剖面描述. 中国标准出版社, 北京.]

Lü GH, Li RP, Wen RH, Xie YB, Wang XY (2014). Analysis of climatic effects on the components of forest litterfall production. Chinese Agricultural Science Bulletin, 30, 1-6. (in Chinese with English abstract) [吕国红, 李荣平, 温日红, 谢艳兵, 王笑影 (2014). 森林调落物组分的气 象影响分析. 中国农学通报, 30,1-6.]

Ma YZ, Cheng DL, Zhong QL, Jin BJ, Xu CB, Hu B (2013). Allometric relationships among different components of forest litterfall in China. Chinese Journal of Plant Ecology, 37, 1071-1079. (in Chinese with English abstract) [马玉珠, 程栋梁, 钟全林, 靳冰洁, 徐朝斌, 胡波 (2013). 中国森林凋落物不同组分异速比例关系. 植物生态学报, 37, 1071-1079.]

Marty C, Houle D, Gagnon C (2015). Variation in stocks and distribution of organic C in soils across 21 eastern Canadian temperate and boreal forests. Forest Ecology and Management, 345, 29-38.

Matthews E (1997). Global litter production, pools, and turnover times: Estimates from measurement data and regression models. Journal of Geophysical Research: Atmospheres, 102, 18771-18800.

Ministry of Environmental Protection of the People's Republic of China, Chinese Academy of Sciences (2015). Regionalization of the National Ecological Function in China (Revised Edition). [中华人民共和国环境保护部, 中国科学院 (2015). 全国生态功能区划 (修编版)]. http://www.zhb.gov.cn/gkml/hbb/bgg/201511/t20151126_ 317777.htm. Cited: 2016-06-14.

Parsons SA, Congdon RA, Lawler IR (2014a). Determinants of the pathways of litter chemical decomposition in a tropical region. New Phytologist, 203, 873-882.

Parsons SA, Congdon RA, Shoo LP, Valdez-Ramirez V, Williams SE (2014b). Spatial variability in litterfall, litter standing crop and litter quality in a tropical rain forest region. Biotropica, 46, 378-386.

Peng SL, Liu Q (2002). The dynamics of forest litter and its responses to global warming. Acta Ecologica Sinica, 22, 1534-1544. (in Chinese with English abstract) [彭少麟, 刘强 (2002). 森林调落物动态及其对全球变暖的响应. 生态学报, 22, 1534-1544.]

Piao S, Fang J, Ciais P, Peylin P, Huang Y, Sitch S, Wang T
(2009). The carbon balance of terrestrial ecosystems in China. Nature, 458, 1009-1013.

Pitkänen A, Simola H, Turunen J (2012). Dynamics of organic matter accumulation and decomposition in the surface soil of forestry-drained peatland sites in Finland. Forest Ecology and Management, 284, 100-106.

Portillo-Estrada M, Pihlatie M, Korhonen JF, Levula J, Frumau AK, Ibrom A, Lembrechts JJ, Morillas L, Horváth L, Jones SK (2016). Climatic controls on leaf litter decomposition across European forests and grasslands revealed by reciprocal litter transplantation experiments. Biogeosciences, 13, 1621-1633.

Ray-Mukherjee J, Nimon K, Mukherjee S, Morris DW, Slotow R, Hamer M (2014). Using commonality analysis in multiple regressions: A tool to decompose regression effects in the face of multicollinearity. Methods in Ecology and Evolution, 5, 320-328.

Salinas N, Malhi Y, Meir P, Silman M, Roman Cuesta R, Huaman J, Salinas D, Huaman V, Gibaja A, Mamani M (2011). The sensitivity of tropical leaf litter decomposition to temperature: Results from a large-scale leaf translocation experiment along an elevation gradient in Peruvian forests. New Phytologist, 189, 967-977.

Schreeg LA, Mack MC, Turner BL (2013). Nutrient-specific solubility patterns of leaf litter across 41 lowland tropical woody species. Ecology, 94, 94-105.

Simmons JA, Fernandez IJ, Briggs RD, Delaney MT (1996). Forest floor carbon pools and fluxes along a regional climate gradient in Maine, USA. Forest Ecology and Management, 84, 81-95.

Sun X, Kang H, Chen HYH, Berg B, Bartels SF, Liu C (2016). Biogeographic patterns of nutrient resorption from Quercus variabilis Blume leaves across China. Plant Biology, 18, 505-513.

Tang SS, Yang WQ, Yin R, Xiong L, Wang HP, Wang B, Zhang Y, Peng YJ, Chen QS, Xu ZF (2014). Spatial characteristics in decomposition rate of foliar litter and controlling factors in Chinese forest ecosystems. Chinese Journal of Plant Ecology, 38, 529-539. (in Chinese with English abstract) [唐仕姗, 杨万勤, 殷睿, 熊莉, 王海鹏, 王滨, 张艳, 彭艳君, 陈青松, 徐振锋 (2014). 中国森 林生态系统调落叶分解速率的分布特征及其控制因子. 植物生态学报, 38, 529-539.]

Technical Manual Writing Group of Ecosystem Carbon Sequestration Project (2015). Observation and Investigation for Carbon Sequestration in Terrestrial Ecosystems. Science Press, Beijing. (in Chinese) [生态系 统固碳项目技术规范编写组 (2015). 生态系统固碳观 测与调查技术规范. 科学出版社, 北京.]

Twilley RW, Lugo AE, Patterson-Zucca C (1986). Litter production and turnover in basin mangrove forests in southwest Florida. Ecology, 67, 670-683.

www.plant-ecology.com 
Vergutz L, Manzoni S, Porporato A, Novais RF, Jackson RB (2012). Global resorption efficiencies and concentrations of carbon and nutrients in leaves of terrestrial plants. Ecological Monograph, 82, 205-220.

Wang SL, Chen CY (2010). The Ecology of Forest Litter. Science Press, Beijing. (in Chinese) [汪思龙, 陈楚莹 (2010). 森林残留物生态学. 科学出版社, 北京.]

Wen D, He NP (2016). Spatial patterns of litter density and their controlling factors in forest and grasslands of China. Acta Ecologica Sinica, 36, 2876-2884. (in Chinese with English abstract) [温丁, 何念鹏 (2016). 中国森林和草 地调落物现存量的空间分布格局及其控制因素. 生态 学报, 36, 2876-2884.]

Westcott V, Enright N, Miller B, Fontaine J, Lade J, Lamont B (2014). Biomass and litter accumulation patterns in species-rich shrublands for fire hazard assessment. International Journal of Wildland Fire, 23, 860-871.

Wu ZY (1980). Vegetation of China. Science Press, Beijing. (in Chinese) [吴征镒 (1980). 中国植被. 科学出版社, 北 京.]

Yan ER, Wang XH, Zhou W (2008). Characteristics of litterfall in relation to soil nutrients in mature and degraded evergreen broad-leaved forests of Tiantong, East China. Journal of Plant Ecology (Chinese Version), 32, 1-12. (in Chinese with English abstract) [阎恩荣, 王希华, 周武 (2008). 天童常绿阔叶林不同退化群落的调落物特征及 与土壤养分动态的关系. 植物生态学报, 32, 1-12.]

Zhang D, Hui D, Luo Y, Zhou G (2008). Rates of litter decomposition in terrestrial ecosystems: Global patterns and controlling factors. Journal of Plant Ecology, 1, 85-93.

Zhang X, Wang W (2015). Control of climate and litter quality on leaf litter decomposition in different climatic zones. Journal of Plant Research, 128, 791-802.

Zhang XP, Wang XP, Zhu B, Zong ZJ, Peng CH, Fang JY (2008). Litter fall production in relation to enviromental factors in northeast China's forests. Journal of Plant Ecology (Chinese Version), 32, 1031-1040. (in Chinese with English abstract) [张新平, 王襄平, 朱彪, 宗占江, 彭长辉, 方精云 (2008). 我国东北主要森林类型的调落 物产量及其影响因素. 植物生态学报, 32, 1031-1040.]

Zhao HM, Huang G, Ma J, Li Y, Zhou L (2012). Responses of surface litter decomposition to seasonal water addition in desert. Chinese Journal of Plant Ecology, 36, 471-482. (in Chinese with English abstract) [赵红梅, 黄刚, 马健, 李 彦, 周丽 (2012). 荒漠区地表调落物分解对季节性降水 增加的响应. 植物生态学报, 36, 471-482.]

Zheng L, Lu LH (2012). Standing crop and nutrient characteristics of forest floor litter in China. Journal of Northwest Forestry University, 27, 63-69. (in Chinese with English abstract) [郑路, 卢立华 (2012). 我国森林 地表调落物现存量及养分特征. 西北林学院学报, 27 , 63-69.]

Zhou X, Talley M, Luo Y (2009). Biomass, litter, and soil respiration along a precipitation gradient in southern Great Plains, USA. Ecosystems, 12, 1369-1380.

特邀编委: 代力民 责任编辑: 王 葳

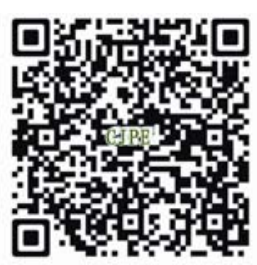

植物生态学报官网

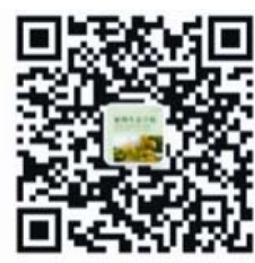

微信订阅号

期刊及学科

相关信息发布

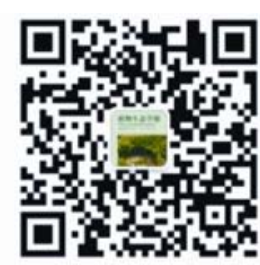

微信服务号

稿件状态查询

全文检索浏览 